7-15-1991

\title{
Solutal Partition Coefficients in Nickel-Based Superalloy \\ PWA-1480
}

\author{
Surendra N. Tewari \\ Cleveland State University
}

M. Vijayakumar

Cleveland State University

Follow this and additional works at: https://engagedscholarship.csuohio.edu/encbe_facpub

Pear Ff $_{\text {tree }}$ Materials Science and Engineering Commons, and the Transport Phenomena Commons NASA Marshall Space Flight Center

How does access to this work benefit you? Let us know!

\section{P.eablisherir's Statement}

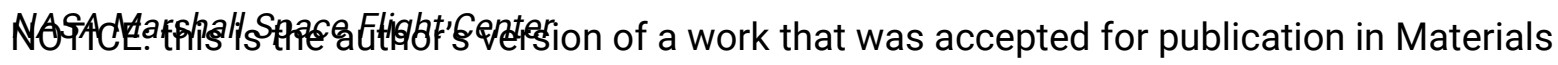

Science and Engineering A. Changes resulting from the publishing process, such as peer review, editing, corrections, structural formatting, and other quality control mechanisms may not be reflected in this document. Changes may have been made to this work since it was submitted for publication. A definitive version was subsequently published in Materials Science and Engineering A, 141, 1-2, (July 15, 1991)] DOI 10.1016/0921-5093(91)90713-W

\section{Original Citation}

Tewari, S., Vijayakumar, M., Lee, J., , \& Curreri, P. (1991). Solutal partition coefficients in nickel-based superalloy PWA-1480. Materials Science \& Engineering A, 141(1), 97-102. doi:10.1016/ 0921-5093(91)90713-W

\section{Repository Citation}

Tewari, Surendra N.; Vijayakumar, M.; Lee, James E.; and Curreri, P. A., "Solutal Partition Coefficients in Nickel-Based Superalloy PWA-1480" (1991). Chemical \& Biomedical Engineering Faculty Publications. 51.

https://engagedscholarship.csuohio.edu/encbe_facpub/51

This Article is brought to you for free and open access by the Chemical \& Biomedical Engineering Department at EngagedScholarship@CSU. It has been accepted for inclusion in Chemical \& Biomedical Engineering Faculty Publications by an authorized administrator of EngagedScholarship@CSU. For more information, please contact library.es@csuohio.edu. 


\title{
Solutal partition coefficients in nickel-based superalloy PWA-1480
}

\author{
S. N. Tewari and M. Vijayakumar \\ Chemical Engineering Department, Cleveland State University, Cleveland, OH 44115 (U.S.A.) \\ J. E. Lee and P. A. Curreri \\ NASA-Marshall Space Flight Center, Huntsville, AL 35812 (U.S.A.)
}

\begin{abstract}
Solutal profiles in dendritic single-crystal specimens of PWA-1480 nickel-base superalloy, which were directionally solidified and quenched, were examined on several transverse cross-sections to obtain the partition coefficients. Similar to their nickel-base binaries, the partition coefficients of tantalum, titanium, and aluminum were found to be less than unity; those of tungsten and cobalt were greater than unity. The partition coefficients were temperature independent in the range $1584-1608 \mathrm{~K}$. The contribution of solid-state diffusion to microsegregation was observed to be negligible.
\end{abstract}

\section{Introduction}

The directionally solidified (DS) nickel-base superalloy, PWA-1480 (nominal composition in weight per cent, $\mathrm{Ni}-12 \mathrm{Ta}-10.4 \mathrm{Cr}-5 \mathrm{Co}-5 \mathrm{Al}-$ $4 \mathrm{~W}-1.4 \mathrm{Ti}$ ), an important turbine blade material for aircraft engines, is also a prime candidate for engines which use hydrogen as fuel, such as the space shuttle main engine [1]. The purpose of this study was to measure the solutal partition coefficients and their temperature dependence in PWA1480. This information, together with knowledge of the growth rate and thermal gradient dependence of primary and secondary dendrite spacings [2], can then be utilized to predict the microsegregation, macrosegregation and microporosity formation in DS PWA-1480 components with the help of models available in the literature $[3]$.

\section{Experimental details}

Single-crystal PWA-1480 cylindrical specimens $(6.4 \mathrm{~mm}$ diameter) were remelted and directionally solidified in an alumina crucible in flowing argon. Two Pt-Pt13\%Rh thermocouples located in the melt along the specimen length at a spacing of about $1 \mathrm{~cm}$ were used to record the temperature in situ. Other experimental details and the description of the apparatus are presented elsewhere $[2,4]$. The specimens were quenched by spraying water onto the alumina crucible surface, after reaching the steady-state directional solidification conditions. Thermocouples were located so that the specimens were quenched when the top thermocouple was at the liquidus temperature of the alloy $(1610 \mathrm{~K})$. During quench the typical cooling rates were about $50 \mathrm{~K} \mathrm{~s}^{-1}$. The DS samples were metallographically polished and etched (etchant by volume, $33 \%$ nitric acid, $33 \%$ acetic acid, $33 \%$ water and $1 \%$ hydrofluoric acid). They were examined to correlate microstructural features, such as the tip and the base of the primary dendrites, with the temperatures measured by the two thermocouples. The melting and solidification behavior of the alloy was also examined by differential thermal analysis (DTA) in an argon atmosphere using heating and cooling rates of $5 \mathrm{~K} \mathrm{~min}^{-1}$.

An electron microprobe (Applied Research Laboratory, SEMQ) was used to examine the microsegregation across the primary dendrites. Because of the large amount of microprobe data required for this study, the $Z A F$ product (atomic number $Z$, absorption $A$ and fluorescence $F$ ) corrected concentration values obtained from the microprobe measurements were initially used to prepare a calibration scheme, which was used for 
the subsequent analysis of the raw microprobe data, as described in detail in ref. 4 .

\section{Results}

\subsection{Microstructure and alloy characterization}

Figure 1 shows the microstructure of the superalloy PWA-1480, directionally solidified at a growth speed of $0.001 \mathrm{~cm} \mathrm{~s}^{-1}$ with a thermal gradient $G_{1}$ of $122 \mathrm{~K} \mathrm{~cm}^{-1}$ at the liquid-solid interface. The longitudinal section (Fig. 1(a)) shows the well aligned primary dendrites in the mushy zone. Solutal profiles were measured on transverse sections corresponding to the temperatures indicated in this figure. These temperatures were estimated by correlating the temperature profiles from the two thermocouples and the location of the top thermocouple in the longitudinal microstructure with respect to the quenched dendrite tip. The dendrite tip temperature thus obtained, about $1608 \mathrm{~K}$ (beween 1605 and $1610 \mathrm{~K}$ ), is in agreement with the liquidus temperature $(1610 \mathrm{~K})$ measured by DTA. Figures $1(\mathrm{~b})$ and $(\mathrm{c})$ show the details of the interdendritic region on transverse sections corresponding to 1548 and $1553 \mathrm{~K}$. Slowly grown, large blocky eutectic $\gamma^{\prime}$ nodules (containing $\gamma$ phase, dark lines within the nodules [5]) were seen in the sample at locations corresponding to all the temperatures below $1548 \mathrm{~K}$. Only fine $\gamma-\gamma^{\prime}$ eutectic particles, as shown in Fig. 1(c), were observed in the quenched interdendritic regions corresponding to the temperatures higher than $1553 \mathrm{~K}$. This suggests that the last interdendritic solidification occurs in a very narrow temperature range (approximately between 1548 and $1553 \mathrm{~K}$ ), in agreement with the DTA plot.

\subsection{Microsegregation of solutes}

Figure 2 shows the solutal profiles in a transverse section at $1550 \mathrm{~K}$ (dendrite base). The microprobe beam was traversed along an " $X$ " type path [6]. For tantalum, aluminum and titanium, the solute contents are minimum in the core of the primary dendrite and increase towards its periphery, a trend expected for partition coefficients $k$ less than unity. Cobalt and tungsten show the opposite trend. It is interesting to note that the nickel-based binaries for these solutes show similar trends; $k_{\mathrm{Ta}}, k_{\mathrm{Al}}$ and $k_{\mathrm{Ti}}$ are less than unity, and $k_{\mathrm{W}}$ and $k_{\mathrm{Co}}$ are greater than unity [7]. Chromium showed a reasonably uniform distribution across the primary dendrite and has not been studied in this investigation. As detailed in ref. 4 , the isoconcentration contours and microstructures on the transverse sections were used to convert the "distance" data (typically shown in Fig. 2 ) into the fraction solid $f_{\mathrm{s}}$.
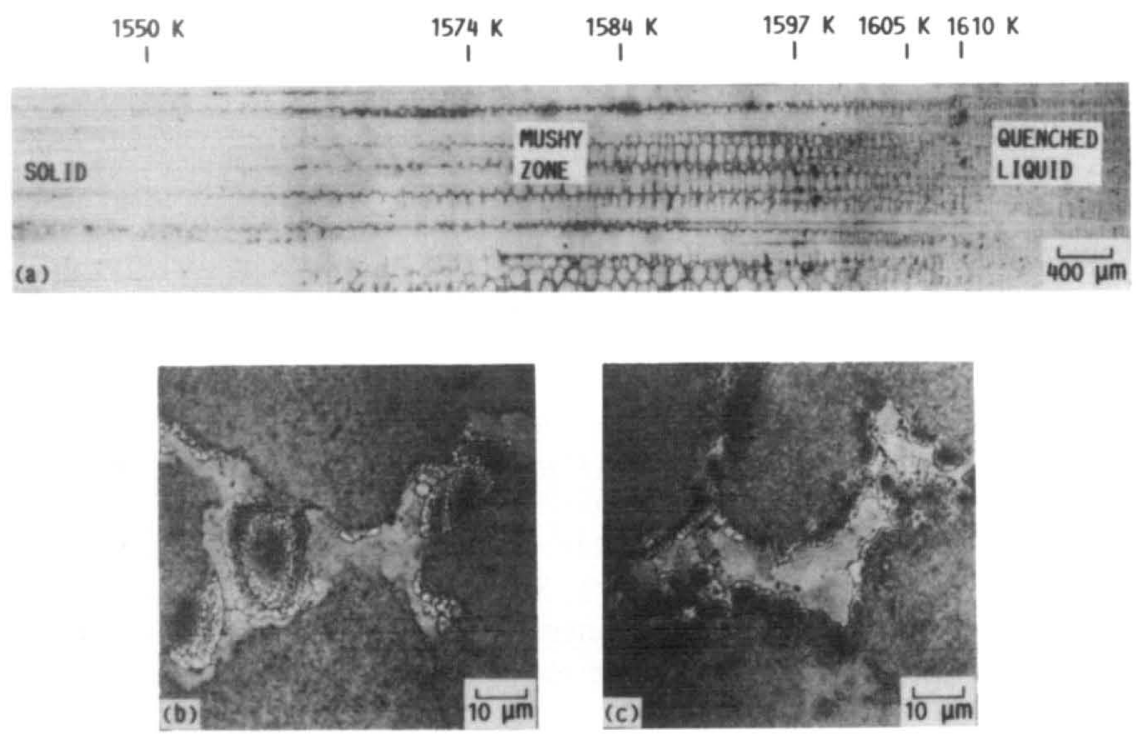

Fig. 1. Microstructure of directionally solidified superalloy PWA-1480, growth speed $0.001 \mathrm{~cm} \mathrm{~s}^{-1}$, thermal gradient in melt at the liquidus temperature $122 \mathrm{~K} \mathrm{~cm}^{-1}:$ (a) longitudinal section, the temperatures obtained by correlating the thermal profiles and the quenched dendrite tips are marked along the mushy zone; (b) and (c) transverse sections near the base of the primary dendrites, at 1548 and $1555 \mathrm{~K}$ respectively. 


\subsubsection{Solute distribution on transverse sections along the length of primary dendrites}

The transverse solutal profiles obtained on typically three to four dendrites, across the two $\mathrm{X}$-type paths in each dendrite cross-section, were averaged to obtain the typical solute concentration $v s$. the corresponding fraction solid $f_{\mathrm{s}}$ relationships shown in Fig. 3. We selected the profiles for tantalum and tungsten to illustrate the typical behaviors of solutes with partition coefficients less than and greater than unity. Figure 3 plots the superposition of elemental profiles corresponding to $1550 \mathrm{~K}$ at the base of primary dendrites, and $1605 \mathrm{~K}$ near their tip. The solute profile for the cross-section near the dendrite tip is identical with that obtained at the base of the dendrite, up to about $12 \%$ fraction solid. The solute content rapidly increases for tantalum and decreases for tungsten in the $1608 \mathrm{~K}$ solutal profile beyond this fraction solid. This sharp change occurs within the primary dendrite arm near its outer surface.

\subsubsection{Sources of scatter}

The scatter in a plot, such as Fig. 3, depends on several factors; the microprobe measurement process (instrumental scatter); scatter due to local microstructural inhomogeneities larger than the probe size (about $3 \mu \mathrm{m}$ ), statistical variation in the primary dendrite size, and their imperfect alignment in the growth direction. The relative standard deviation due to the instrument scatter was observed to be about $\pm 3 \%$ of composition.

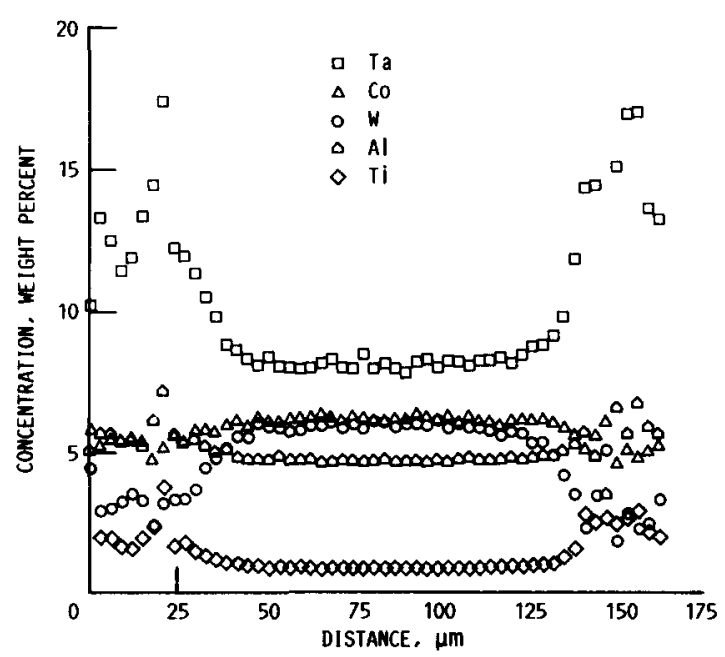

Fig. 2. Typical solute (tantalum, titanium, aluminum, cobalt and tungsten) distributions across primary dendrites along $\mathrm{X}$ type paths [6].
The scatter due to the local microstructural variations is minimal within the primary dendrite, about $\pm 3 \%$ in the dendrite core $\left(f_{\mathrm{s}} \approx 0\right)$, Fig. 3 . However, the scatter in the quenched interdendritic region is much greater $( \pm 10 \%-20 \%)$ because it consists of discrete $\gamma$ and $\gamma^{\prime}$ phases of different compositions. Additional scatter arises from any misalignment of the primary dendrites with the growth direction causing an asymmetrical solute distribution along the two $\mathrm{X}$-type paths across the dendrites. This scatter is zero at $f_{\mathrm{s}} \approx 0$ and increases with increasing $f_{\mathrm{s}}$. Variation in the primary dendrite spacings, typically about $10 \%$ in our samples, is responsible for additional scatter.
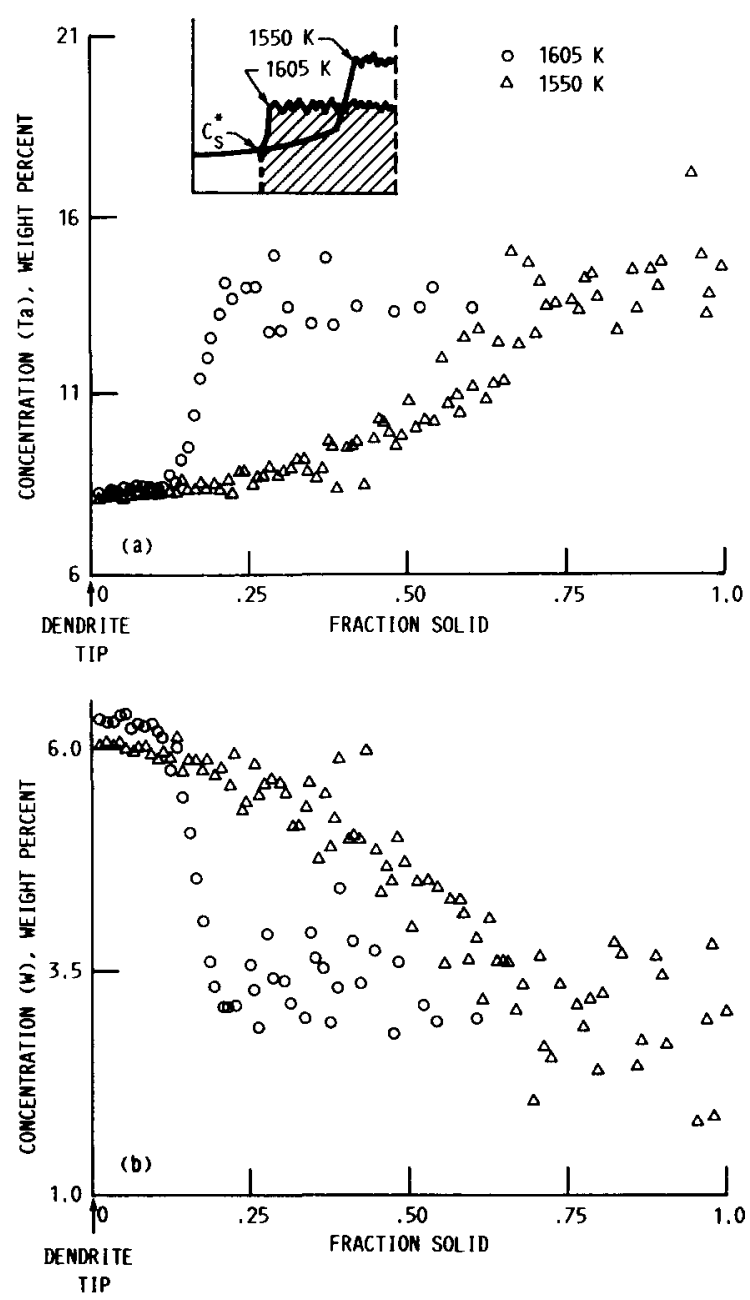

Fig. 3. Superposition of the solutal profiles corresponding to the transverse sections at 1550 and $1605 \mathrm{~K}$. The inset (schematic diagram) shows how $C_{1}$ is obtained by averaging the composition of the interdendritic region (hatched area) to calculate the solute partition coefficients, $k=C_{s}^{*} / C_{1}:$ (a) tantalum, (b) tungsten. 


\subsubsection{Solid-state diffusion}

Superpositions of the solutal profiles obtained from all of the transverse microstructures examined in the mushy zone are plotted for tantalum, titanium, aluminum, cobalt and tungsten in Fig. 4. For the sake of clarity in the presentation, the data corresponding to the quenched interdendritic melt regions (because of the very large scatter) have been eliminated in this figure. The solute contents in the dendrite core $\left(f_{s} \approx 0\right)$ are nearly identical for all the sections. This observation is valid for all the elements, tantalum (Fig. 4(a)), titanium (Fig. 4(b)), aluminum (Fig. 4(c)), cobalt (Fig. 4(d)) and tungsten (Fig. 4(e)), indicating that their solid-state diffusion effects are negligible. In the presence of significant diffusion, the solute content at $f_{s} \approx 0$ would have been higher for the transverse section at the base of the primary dendrite, compared with that near the tip, for tantalum, titanium and aluminum $(k<1)$, and lower for tungsten and cobalt $(k>1)$.

\subsection{Solute partition coefficients}

In order to obtain the partition coefficients, we require $C_{\mathrm{s}}^{*}$, the composition in the solid at the surface of the primary dendrite, and $C_{\mathrm{l}}$, the composition of the interdendritic liquid in equilibrium at that temperature (assuming that there is no transverse solutal gradient in the interdendritic melt). Since the solutal profiles at all the temperatures in the mushy zone follow that at the base of the dendrite until they begin to rise steeply (Fig. $4(\mathrm{a})-(\mathrm{e})), C_{\mathrm{s}}^{*}$ at any temperature is the composition at which its solutal profile takes off for the steep rise. The corresponding $C_{1}$ can be obtained by integrating the rest of the solutal profile at that temperature for compositions beyond $C_{\mathrm{s}}{ }^{*}$ (the region corresponding to the quenched interdendritic melt, shown schematically as the hatched area in the inset of Fig. 3(a)) and obtaining the average value.

The $C_{1}$ and $C_{\mathrm{s}}^{*}$ values thus obtained at several temperatures are compiled in Table 1 . The partition coefficients $\left(C_{\mathrm{s}}^{*} / C_{1}\right)$ for tantalum, titanium, aluminum, cobalt and tungsten for PWA-1480 are also given in this table. Table 1 also lists the partition coefficients reported in the literature for nickel-base alloys: $k_{\mathrm{Al}}$ and $k_{\mathrm{Ta}}$ for the ternary alloy $\mathrm{Ni}-13.1 \mathrm{Al}-5.1 \mathrm{Ta}$ [8], $k_{\mathrm{Cr}}, k_{\mathrm{W}}$ and $k_{\mathrm{Ti}}$ for MAR-M200 [9], and $k_{\mathrm{Co}}$ for Waspalloy [10], and those for the nickel-base binaries [7]. Table 1 shows that the solute partition coefficients of all these elements in PWA-1480 are reasonably constant in the temperature range investigated. It also shows that the partition coefficients show similar trends in all the alloys $(k<1$ for titanium, tantalum and aluminum and $k>1$ for tungsten and cobalt). However, there are significant quantitative differences among the partition coefficients in these alloys for the same solutes. This makes it imperative to make independent solutal partition coefficient measurements for the commercial alloy of interest, if one wishes to model and predict its processing parameter dependence of microsegregation, macrosegregation and microporosity formation.

\section{Summary of results}

PWA-1480, despite being a multicomponent complex alloy, has solidification behavior similar to that of a binary (the last interdendritic melt freezes nearly isothermally, within a narrow temperature range of about $5 \mathrm{~K}$ ). For the growth conditions of $G_{1}=122 \mathrm{~K} \mathrm{~cm}^{-1}$ and growth speed of $0.001 \mathrm{~cm} \mathrm{~s}^{-1}$ examined in this study, the solidstate diffusion contribution to the microsegregation is negligible. Similar to their nickel-base binaries, the partition coefficients $k$ for tantalum, titanium and aluminum are less than unity $\left(k_{\mathrm{Ta}}=0.6, k_{\mathrm{Ti}}=0.4\right.$ and $\left.k_{\mathrm{Al}}=0.9\right)$; for tungsten and cobalt they are more than unity $\left(k_{\mathrm{W}}=1.7\right.$ and $k_{\mathrm{Co}}=1.1$ ). The solute partition coefficients appear to be independent of the temperature from 1584 to $1610 \mathrm{~K}$.

\section{Acknowledgment}

This work was supported by a grant (NAG-8091) from NASA-Marshall Space Flight Center, with Center Director Discretionary Fund-87-14. Research facilities in the Microgravity Materials Science Laboratory at NASA-Lewis Research Center were used during this study. Appreciation is expressed to Francis M. Terepka for assistance in microprobe analysis, to Guy Smith, University of Alabama, Huntsville for technical assistance, and to Professor David R. Poirier, University of Arizona and Henry de Groh of NASA-Lewis Research Center for a critical review. 

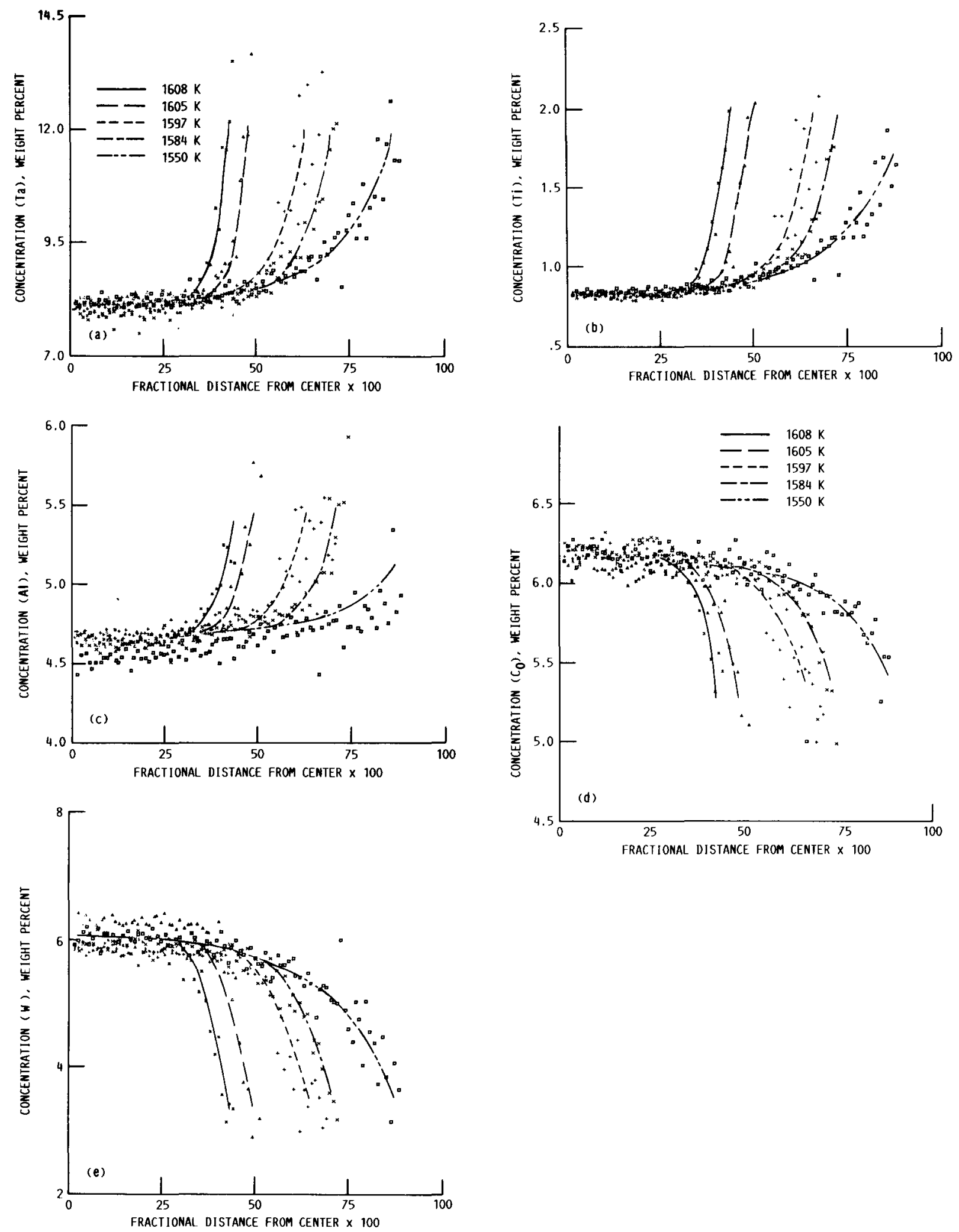

Fig. 4. Superposition of solutal profiles on transverse sections corresponding to $1550,1584,1597,1605$, and $1608 \mathrm{~K}$ (the quenched interdendritic portions of the solutal profiles were deleted for clarity of presentation: (a) tantalum, (b) titanium, (c) aluminum, (d) cobalt, (e) tungsten. 


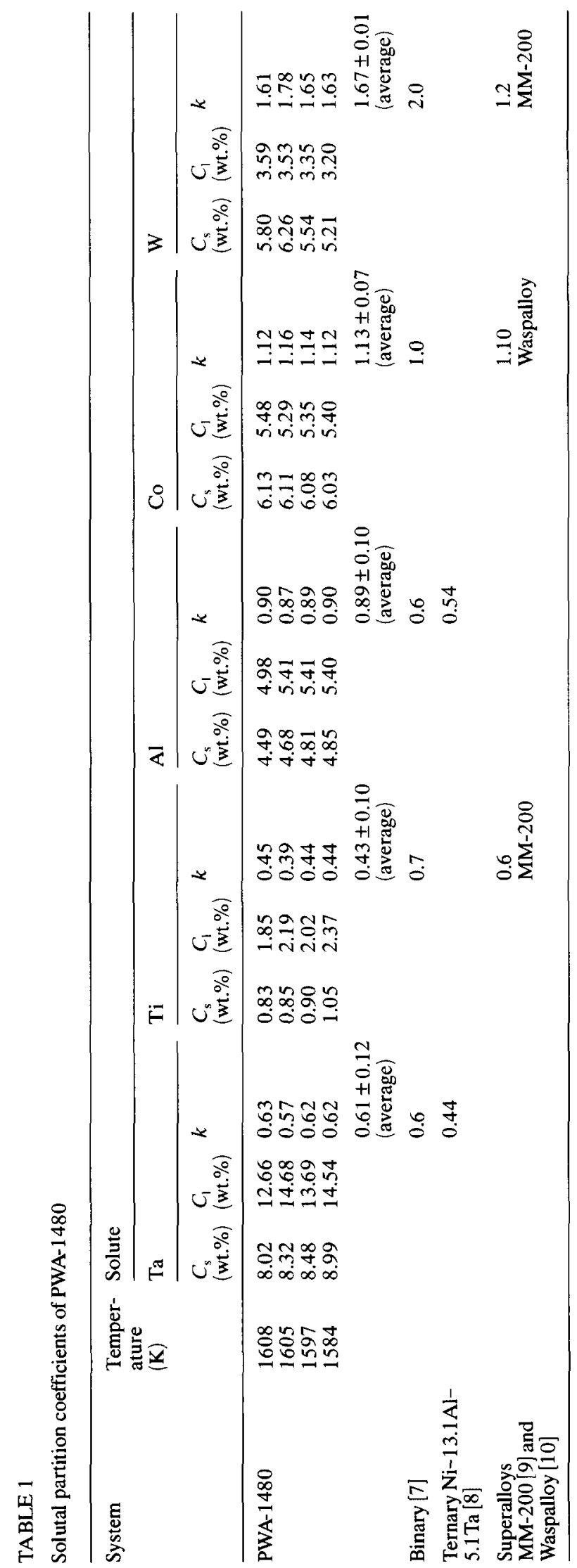

\section{References}

1 R. L. Dreshfield and R. A. Parr, Application of single crystal superalloys for earth-to-orbit propulsion systems, NASA-TM 89877, 1987 (NASA-Lewis Research Center, Cleveland, $\mathrm{OH}$ ).

2 M. Vijayakumar, S. N. Tewari, J. E. Lee and P. A. Curreri, Dendrite spacings in directionally solidified superalloy PWA-1480, Mater. Sci. Eng., 132 (1991) 195-201.

3 D. R. Poirier and K. Yeum, Predicting microporosity in nickel base DS castings, 35th Ann. Meet. of the Investment Casting Institute, Washington, DC, October 5-7, 1987.

4 S. N. Tewari, M. Vijayakumar, J. E. Lee and P. A. Curreri, Dendrite morphology and microsegregation in directionally solidified superalloy, PWA-1480, single crystal: effect of gravity, NASA-TM 103518, 1990 (George C. Marshall Space Flight Center, AL).

5 J. E. Doherty, B. H. Kear and A. F. Giamei, J. Met., 23 (November 1971) 59-62.

6 T. Z. Kattamis and M. C. Flemings, Trans. TMS-AIME, 233(1965) 992-999.

7 Metals Handbook, Vol. 8, American Society for Metals, Metals Park, OH, 1973, 8th edn., pp. 258, 262, 291, 326.

8 R. Kadalbal, J. J. Montoya-Cruz and T. Z. Kattamis, Metall. Trans. A, 11 (1980) 1547-1553.

9 R. Sellamuthu, Ph.D. Thesis, University of Pittsburgh, Pittsburgh, PA, 1979.

10 C. L. Jeanfils, J. H. Chen and H. J. Klein, in H. D. Brody and D. A. Apelian (eds.), Modeling of Casting and Welding Processes, TMS-AIME, Warrendale, PA, 1981, pp. 313-332. 